\title{
Official control of pesticide residues in crops from the north-eastern Poland in 2012
}

\section{Kontrola urzędowa pozostałości środków ochrony roślin w płodach rolnych północno-wschodniej Polski w 2012 roku}

\author{
Bożena Łozowicka, Izabela Hrynko, Ewa Rutkowska, Magdalena Jankowska, Piotr Kaczyński
}

\section{Summary}

This paper presents results of official control of pesticide residues conducted in the samples from the north-eastern Poland. In total 117 samples were tested in the year 2012 (62.4\% vegetables, 26.5\% fruit and $11.1 \%$ cereals grain). Among 167 pesticides, 11 active substances were detected, mainly fungicides ( $91.9 \%$ of detection). Pesticide residues most often were detected in samples of fruit (32.3\%), especially in strawberries (25.8\%). $18.8 \%$ (22) samples contained pesticide residues below maximum residue levels (MRLS). MRLs exceedances were not found.

Key words: crops, official control, pesticide residues, north-eastern Poland

\section{Streszczenie}

Celem opracowania jest analiza wyników przeprowadzonej kontroli urzędowej w płodach rolnych z północno-wschodniej Polski na obecność pozostałości środków ochrony roślin (ś.o.r.). W 2012 roku przebadano 117 próbek (62,4\% warzyw, 26,5\% owoców i 11,1\% ziaren zbóż). Spośród 167 oznaczanych pestycydów wykryto 11 substancji czynnych, głównie fungicydów (91,9\% detekcji). Pozostałości ś.o.r. najczęściej wykrywano w próbkach owoców (32,3\%), a pośród nich w truskawkach (25,8\%). W 18,8\% próbek stwierdzono pozostałości poniżej najwyższych dopuszczalnych poziomów (NDP). Nie stwierdzono przekroczeń NDP.

Słowa kluczowe: płody rolne, kontrola urzędowa, pozostałości pestycydów, północno-wschodnia Polska

Instytut Ochrony Roślin - Państwowy Instytut Badawczy

Terenowa Stacja Doświadczalna

Laboratorium Badania Pozostałości Środków Ochrony Roślin

Chełmońskiego 22, 15-195 Białystok

B.Lozowicka@iorpib.poznan.pl; biuro@ior.bialystok.pl 


\section{Wstęp / Introduction}

Stosowanie chemicznych środków ochrony roślin (ś.o.r.) stanowi najpowszechniej wykorzystywaną metodę ochrony roślin przed chorobami, szkodnikami i chwastami. Ze względu na możliwość wystąpienia pozostałości powyżej dopuszczalnych limitów, niezbędne jest zapewnienie właściwej ochrony zdrowia ludzi i zwierząt poprzez prowadzenie kontroli i monitoringu pozostałości tych związków w uprawach rolnych.

Część badań, w ramach programu wieloletniego (20112015) „Ochrona roślin uprawnych z uwzględnieniem bezpieczeństwa żywności oraz ograniczenia strat w plonach i zagrożeń dla zdrowia ludzi, zwierząt domowych i środowiska" zlecona przez Państwową Inspekcję Ochrony Roślin i Nasiennictwa, prowadzona jest w Laboratorium Badania Pozostałości Srodków Ochrony Roślin Instytutu Ochrony Roślin - Państwowego Instytutu Badawczego (IOR - PIB) w Białymstoku.

Celem pracy jest prezentacja wyników badań dotyczących występowania pozostałości ś.o.r. w próbkach owoców, warzyw i zbóż pobranych w 2012 roku z północnowschodniej Polski oraz porównanie oznaczonych stężeń do najwyższych dopuszczalnych poziomów pozostałości (NDP). Ponadto ocenie poddano wykryte substancje czynne (s.cz.) pod kątem zgodności rejestracji w danej uprawie.

W prowadzonych badaniach oceniono częstotliwość występowania pozostałości ś.o.r. w próbkach, jak również rodzaje wykrytych s.cz. Przedstawiono liczbę próbek wolnych od pozostałości oraz próbki z pozostałościami ś.o.r.

\section{Materiały i metody / Materials and methods}

Materiał do badań stanowiło 117 próbek, w tym 73 warzyw $(62,4 \%), 31$ owoców $(26,5 \%)$ i 13 zbóż
$(11,1 \%)$. Próbki pobrane losowo przez inspektorów Wojewódzkich Inspektoratów Ochrony Roślin i Nasiennictwa (WIORiN) zgodnie $\mathrm{z}$ programem kontroli urzędowej, zróżnicowanym dla poszczególnych upraw, pochodziły z 2 województw północno-wschodniej Polski: podlaskiego - 87 próbek $(74,4 \%)$ i warmińskomazurskiego - $30(25,6 \%)$. W badaniach analitycznych poszukiwano pozostałości 167 pestycydów: 60 fungicydów, 82 insektycydów oraz 25 herbicydów (tab. 1).

Do oznaczania stosowano akredytowane metody analityczne umożliwiające analizę wielu związków jednocześnie, zgodnie $\mathrm{z}$ obowiązującym przewodnikiem SANCO (SANCO 2011). Poprawność metod sprawdzano systematycznie poprzez udział w międzynarodowych badaniach biegłości (PT - Proficiency Test) organizowanych przez FAPAS (The Food Analysis Performance Assessment Scheme), Unię Europejską (European Comission's Proficiency Test on Pesticide Residues in Fruit and Vegetables) oraz Zakład Badania Pozostałości Środków Ochrony Roślin IOR - PIB w Poznaniu. Analogicznie do lat ubiegłych, w omawianym okresie badawczym Laboratorium uzyskało poprawne wyniki. Dowodzi to, iż system kontroli poziomu pozostałości jest prawidłowy i zapewnia uzyskiwanie rzetelnych wyników badań.

Jakościowe i ilościowe oznaczenia pozostałości wykonano techniką chromatografii gazowej (GC - gas chromatography) z wykorzystaniem dwóch detektorów selektywych: EC (electron capture - wychwytu elektronów) i NP (nitrogen-phosphorus - azotowo-fosforowy) (Łozowicka 2010) oraz wysokosprawnej chromatografii cieczowej (HPLC - High Performance Liquid Chromatography) w dualnym systemie detekcji (Łozowicka i Kaczyński 2009). Pozostałości ditiokarbaminianów, wyrażone jako $\mathrm{CS}_{2}$ oznaczano spektrofotometrycznie (Chmiel 1979).

Tabela 1. Analizowane substancje czynne ś.o.r.

Table 1. Analysed active substances

acetamiprid; acrinathrin; aldrin; alpha-cypermethrin; alpha-endosulfan; alpha-HCH; azinphos-ethyl; azinphosmethyl; beta-cyfluthrin; beta-endosulfan; beta-HCH; bifenthrin; bromopropylate; bromophos-ethyl; bromophosmethyl; buprofezin; cadusafos; carbaryl; carbofuran; chlorfenvinphos; chlorpyrifos; chlorpyrifos-methyl; coumaphos; cyfluthrin; cypermethrin; deltamethrin; diazinon; dicofol; dieldrin; dimethoate; endosulfan-sulfate; Insektycydy $\quad$ endrin; esfenvalerate; ethion; ethoprophos; fenazaquin; fenchlorphos; fenitrothion; fenpropathrin; fenvalerate; Insecticides $\quad$ fipronil; formothion; gamma-HCH (lindane); HCB; heptachlor; heptachlor-epoxide; heptenophos; hexythiazox; indoxacarb; isofenphos; isofenphos-methyl; lambda-cyhalothrin; malaoxon; malathion; mecarbam; methacrifos; mevinphos; methidathion; methoxychlor (DMDT); DDT (o,p'-DDT, p,p'-DDD, p,p'-DDE, p,p'-DDT); paraoxonethyl; paraoxon-methyl; parathion-ethyl; parathion-methyl; permethrin; phosalone; phosmet; pirimicarb; pirimiphos; pirimiphos-methyl; profenofos; propoxur; pyridaben; pyriproxyfen; tau-fluvalinate; tebufenpyrad; teflubenzuron; tetrachlorvinphos; tetradifon; thiacloprid, thiamethoxam; triazophos; zeta-cypermethrin

azaconazole; azoxystrobin; benalaxyl; bitertanol; boscalid; bupirimate; captan; carbendazim; chlorothalonil; cymoxanil; cyproconazole; cyprodinil; dichlofluanid; dicloran; difenoconazole; dimethomorph; dimoxystrobin; diniconazole; diphenylamine; dithiocarbamates*; epoxiconazole; fenamidone; fenarimol; fenbuconazole; Fungicydy fenchlorphos; fenhexamid; fenpropimorph; fludioxonil; fluquinconazole; flusilazole; flutriafol; folpet; Fungicides $\quad$ imibenconazole; iprodione; iprovalicarb; kresoxim-methyl; mepanipyrim; metalaxyl; myclobutanil; oxadixyl; paclobutrazol; penconazole; picoxystrobin; prochloraz; procymidone; propiconazole; pyraclostrobin; pyrimethanil; quinoxyfen; quintozene; tebuconazole; tecnazene; tetraconazole; tolclofos-methyl; tolylfluanid; triadimefon; triadimenol; trifloxystrobin; vinclozolin; zoxamide

Herbicydy Herbicides

acetochlor; atrazine; chlorpropham; clomazone; cyanazine; cyprazine; dichlobenil; diflufenican; fluazifop-p-butyl; flurochloridone; lenacil; linuron; metamitron; metazachlor; metribuzin; napropamide; pendimethalin; prometryn; propachlor; propaquizafop; propazine; propham; propyzamide; simazine; trifluralin 


\section{Wyniki i dyskusja / Results and discussion}

W 22 badanych próbkach, czyli w 18,8\% ogółu próbek stwierdzono pozostałości ś.o.r. Wolnych od pozostałości było $81,2 \%$ próbek, w tym $64,5 \%$ owoców, $85 \%$ warzyw oraz wszystkie próbki zbóż. Szczegółowe dane dotyczące zakresu wykrytych stężeń i rodzajów pestycydów w płodach rolnych przedstawiono $w$ tabeli 2.

Pozostałości wykrywano najczęściej w próbkach owoców (32,3\%), natomiast o połowę mniej stwierdzono w warzywach $(15,1 \%)$. Najwyższy odsetek próbek zanieczyszczonych stanowiły truskawki $(72,7 \%$ wszystkich próbek truskawek) oraz pomidory $(62,5 \%$ wszystkich próbek pomidorów). Wszystkie oznaczone stężenia pestycydów nie przewyższały najwyższych dopuszczalnych poziomów pozostałości. Spośród 34 badanych asortymentów płodów rolnych w 26 owocach, warzywach i zbożach pozostałości ś.o.r. nie wykryto.

Z 167 pestycydów objętych programem badań oznaczono 11 s.cz. $(6,6 \%)$. Najczęściej wykrywano pozostałości fungicydów, które stanowiły $91,9 \%$ detekcji, z czego najpowszechniej ditiokarbaminiany (32,5\%) (rys. 1). Wśród insektycydów oznaczono pozostałości alfa-cypermetryny $(5,4 \%)$ i esfenwaleratu $(2,7 \%)$.

Tabela 2. Wykryte pozostałości ś.o.r. w płodach rolnych

Table 2. Pesticide residues detected in crops

\begin{tabular}{|c|c|c|c|c|c|c|c|}
\hline \multirow[t]{2}{*}{$\begin{array}{l}\text { Klasyfikacja } \\
\text { Classification }\end{array}$} & \multirow[t]{2}{*}{$\begin{array}{l}\text { Produkt } \\
\text { Product }\end{array}$} & \multirow[t]{2}{*}{$\begin{array}{l}\text { Liczba próbek } \\
\text { (\% próbek) } \\
\text { Number of samples } \\
\text { (percentage } \\
\text { of samples) }\end{array}$} & \multirow[t]{2}{*}{$\begin{array}{c}\text { Próbki } \\
\text { z pozostałościami } \\
<\text { NDP } \\
\text { Samples } \\
\text { with residues } \\
<\text { MRLs } \\
{[\%]}\end{array}$} & \multirow[t]{2}{*}{$\begin{array}{l}\text { Związek } \\
\text { Compound }\end{array}$} & \multicolumn{2}{|c|}{$\begin{array}{c}\text { Zakres } \\
\text { wykrytych } \\
\text { pozostałości } \\
\text { Range } \\
\text { of detected } \\
\text { residues } \\
\text { [mg } / \mathrm{kg}]\end{array}$} & \multirow[t]{2}{*}{$\begin{array}{c}\text { NDP } \\
\text { MRL } \\
{[\mathrm{mg} / \mathrm{kg}]}\end{array}$} \\
\hline & & & & & $\min$. & $\max$. & \\
\hline \multirow{9}{*}{$\begin{array}{l}\text { Owoce świeże } \\
\text { Fresh fruit }\end{array}$} & \multirow{6}{*}{$\begin{array}{l}\text { truskawki } \\
\text { strawberries }\end{array}$} & \multirow{6}{*}{$11(9,4)$} & \multirow{6}{*}{6,8} & boscalid & 0,04 & 0,04 & 10 \\
\hline & & & & cyprodinil & 0,01 & 0,05 & 5 \\
\hline & & & & dithiocarbamates & 0,09 & 0,19 & 10 \\
\hline & & & & fenhexamid & 0,07 & 0,5 & 5 \\
\hline & & & & fludioxonil & 0,01 & 0,05 & 3 \\
\hline & & & & pirimethanil & 0,07 & 0,07 & 5 \\
\hline & \multirow{3}{*}{$\begin{array}{l}\text { porzeczki } \\
\text { currants }\end{array}$} & \multirow{3}{*}{$6(5,1)$} & \multirow{3}{*}{1,7} & alpha-cypermethrin & 0,01 & 0,04 & 0,05 \\
\hline & & & & dithiocarbamates & 0,14 & 0,85 & 5 \\
\hline & & & & esfenvalerate & 0,02 & 0,02 & 0,02 \\
\hline \multirow{10}{*}{$\begin{array}{l}\text { Warzywa } \\
\text { świeże } \\
\text { Fresh } \\
\text { vegetables }\end{array}$} & \multirow{5}{*}{$\begin{array}{l}\text { pomidory } \\
\text { tomatoes }\end{array}$} & \multirow{5}{*}{$8(6,8)$} & \multirow{5}{*}{4,3} & azoksystrobin & 0,03 & 0,03 & 3 \\
\hline & & & & chlorothalonil & 0,03 & 0,11 & 2 \\
\hline & & & & cyprodinil & 0,01 & 0,01 & 1 \\
\hline & & & & dithiocarbamates & 0,12 & 0,46 & 3 \\
\hline & & & & fludioxonil & 0,01 & 0,01 & 1 \\
\hline & $\begin{array}{l}\text { papryka } \\
\text { peppers }\end{array}$ & $2(1,7)$ & 0,9 & dithiocarbamates & 0,08 & 0,08 & 5 \\
\hline & $\begin{array}{l}\text { ogórki } \\
\text { cucumbers }\end{array}$ & $12(10,3)$ & 0,9 & chlorothalonil & 0,03 & 0,03 & 1 \\
\hline & $\begin{array}{l}\text { sałata } \\
\text { lettuce }\end{array}$ & $2(1,7)$ & 1,7 & dithiocarbamates & 0,59 & 0,69 & 5 \\
\hline & $\begin{array}{l}\text { fasola } \\
\text { beans }\end{array}$ & $3(2,6)$ & 0,9 & chlorothalonil & 0,02 & 0,02 & 5 \\
\hline & $\begin{array}{l}\text { pieczarka } \\
\text { mushroom }\end{array}$ & $3(2,6)$ & 0,9 & tebuconazole & 0,01 & 0,01 & 5 \\
\hline
\end{tabular}

NDP - najwyższe dopuszczalne poziomy pozostałości - MRLs - Maximum Residue Levels 


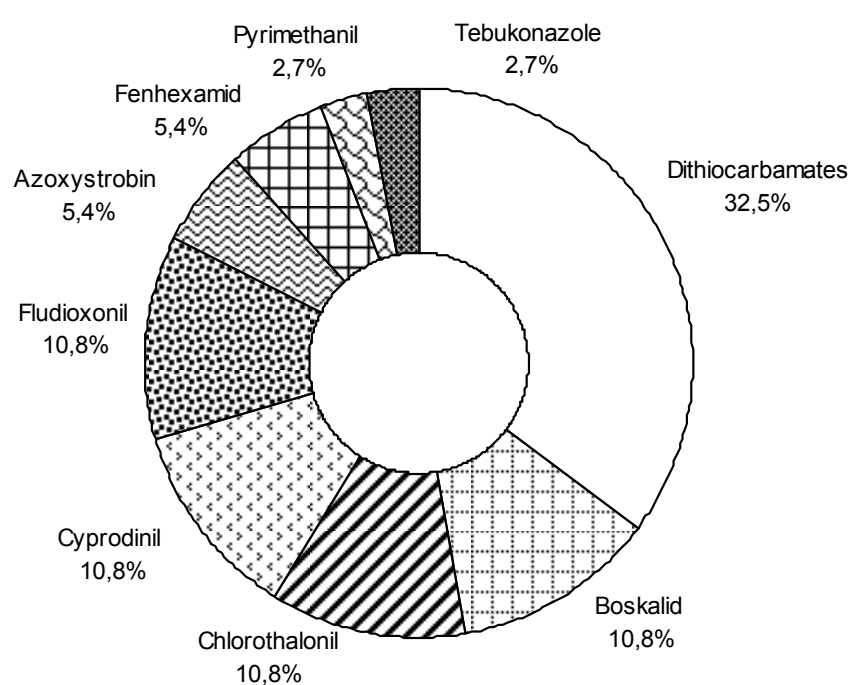

Rys. 1. Częstotliwość wykrywania fungicydów w próbkach owoców i warzyw

Fig. 1. Frequency of detection of fungicide residues in samples of fruits and vegetables

Spośród próbek zawierających pozostałości ś.o.r. przeważający odsetek stanowiły takie, w których oznaczono jeden związek (13 próbek). Odsetek próbek wielopozostałościowych przedstawiono na rysunku 2. Dwie s.cz. stwierdzono w 4 próbkach, z czego 3 stanowiły truskawki i 1 pomidora. Trzy s.cz. wystąpiły w 3 próbkach (2 truskawek i 1 porzeczek). Cztery s.cz. oznaczono w 1 próbce truskawek i 1 pomidora. W próbce truskawek wykryto boskalid w stężeniu $0,04 \mathrm{mg} / \mathrm{kg}$, cyprodinil $0,05 \mathrm{mg} / \mathrm{kg}$, fludioksonil $0,05 \mathrm{mg} / \mathrm{kg} \mathrm{i}$ pirymetanil $0,07 \mathrm{mg} / \mathrm{kg}$, w pomidorze zaś azoksystrobinę w stężeniu $0,03 \mathrm{mg} / \mathrm{kg}$, chlorotalonil $0,11 \mathrm{mg} / \mathrm{kg}$, cyprodinil $0,01 \mathrm{mg} / \mathrm{kg}$ oraz fludioksonil $0,01 \mathrm{mg} / \mathrm{kg}$.
Najczęściej wykrywanymi kombinacjami były połączenia fungicydów: cyprodinil/fludioksonil (w 4 próbkach) oraz kaptan/ditiokarbaminiany (w 2 próbkach).

W 2012 roku, w Polsce północno-wschodniej, w porównaniu do lat ubiegłych, zmniejszył się odsetek próbek płodów rolnych zanieczyszczonych pozostałościami ś.o.r. i był zdecydowanie najniższy od 2008 roku. W roku 2011 wyniósł 33,1\%, w 2010 r. - 28,3\%, w 2009 r. - 38,3\%, natomiast w 2008 roku - 45,5\% (Łozowicka i wsp. 2012). Ponadto, w przebadanych próbkach, nie stwierdzono przekroczeń NDP pozostałości ś.o.r. zgodnie z Rozporządzeniem (WE) Parlamentu Europejskiego i Rady Unii Europejskiej (Rozporządzenie 2005) oraz stosowania preparatów niedozwolonych (Ustawa 2003). W tym rejonie kraju utrzymuje się nadal pozytywna tendencja spadkowa liczby powiadomień informacyjnych $\mathrm{w}$ ramach systemu RASFF (Rapid Alert System for Food and Feed) (Łozowicka i wsp. 2011).

W celu porównania stopnia zanieczyszczenia pestycydami płodów rolnych $\mathrm{z}$ północno-wschodniej Polski, najbardziej miarodajnym wydaje się odniesienie wyników badań do monitoringu krajowego. Analizy wykonywano w laboratoriach o podobnych możliwościach analitycznych i jednakowych programach badań. Według danych literaturowych, częstość występowania pozostałości ś.o.r. w krajowej produkcji pierwotnej w roku 2011 była również niższa niż w latach ubiegłych (Nowacka i wsp. 2009, 2010, 2011, 2012), a pestycydy wykrywano na niskim poziomie pozostałości ś.o.r. oraz w niewielkiej liczbie badanych próbek. Na taki wynik mógł mieć wpływ rodzaj badanych próbek, gdyż znaczący odsetek próbek w krajowym monitoringu stanowiły próbki zbóż, które są w mniejszym stopniu poddawane zabiegom ochrony roślin niż owoce i warzywa.

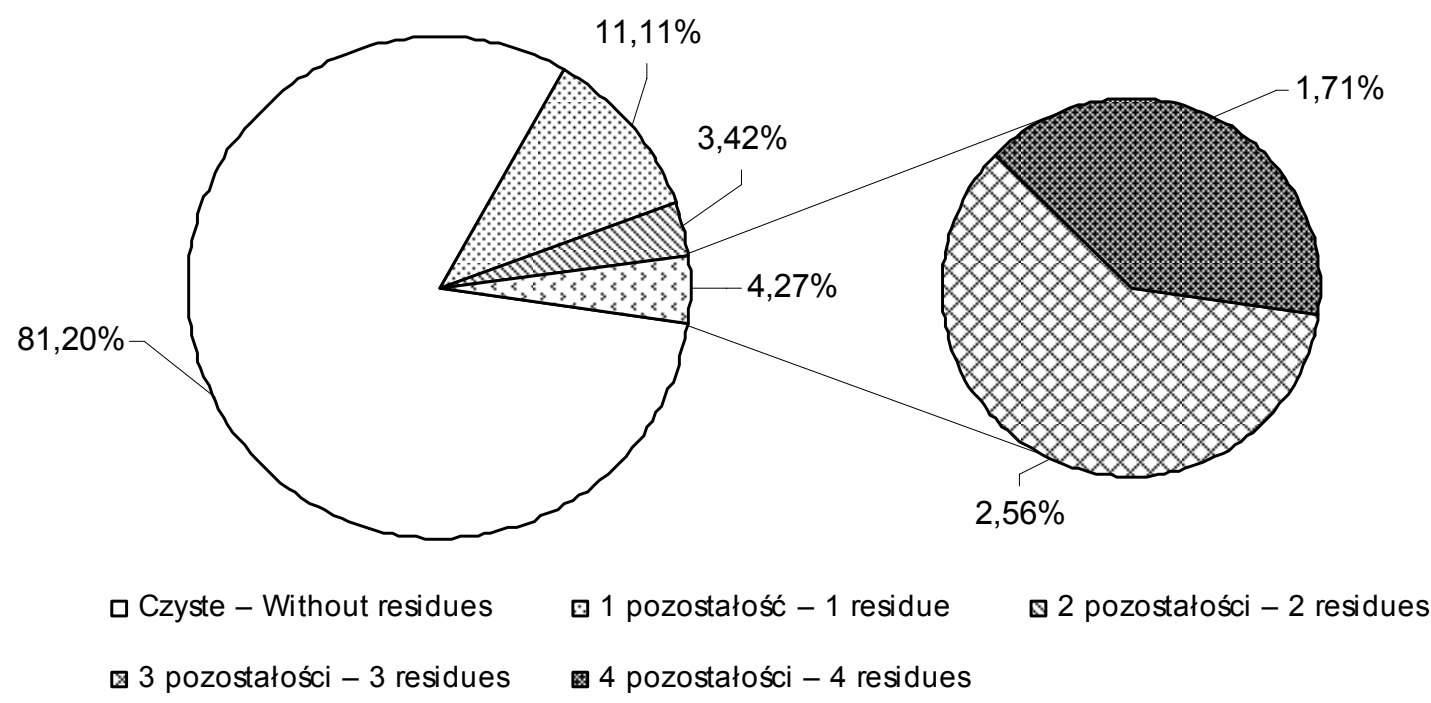

Rys. 2. Procent próbek wielopozostałościowych

Fig. 2. Percentage of samples with multiresidues 


\section{Podsumowanie / Summation}

1. W prowadzonej od wielu lat kontroli urzędowej, rok 2012 jest pierwszym, w którym w płodach rolnych północno-wschodniej Polski, nie stwierdzono przekroczeń NDP oraz stosowania preparatów niedozwolonych. Na taką sytuację mógł mieć wpływ rodzaj badanych próbek, gdyż znaczącą grupę stanowiły warzywa oraz zboża, mniej intensywnie chronione chemicznie.

2. Oceniono, iż owoce wnoszą największy odsetek próbek z pozostałościami $(35,5 \%)$, warzywa dwukrotnie mniejszy $-15,1 \%$, natomiast zboża są całkowicie wolne od pozostałości. Podobną tendencję zaobserwowano również w latach ubiegłych. Potwierdza to fakt, iż owoce należą do upraw poddawanych licznym zabiegom chemicznym, co z kolei przyczynia się do występowania w nich największego odsetka próbek z pozostałościami.

3. Najczęściej wykrywaną grupą pestycydów były fungicydy. Można stąd wnioskować, iż właśnie ta grupa może mieć decydujące znaczenie w zanieczyszczaniu żywności w Polsce północno-wschodniej.
Jednakże fungicydy w przeciwieństwie do insektycydów, czy innych grup pestycydów, są mniej szkodliwe dla środowiska, co ma związek ze stosunkowo niską toksycznością, czy szybkim procesem rozkładu.

4. W stosunku do lat ubiegłych, w 2012 roku stwierdzono niższy odsetek próbek wielopozostałościowych, co w aspekcie bezpieczeństwa żywności niesie mniejsze ryzyko narażenia zdrowia konsumentów.

5. Brak przekroczeń NDP oraz stosowania preparatów niedozwolonych w płodach rolnych może być sygnałem wzrostu świadomości polskich producentów do przestrzegania zaleceń dotyczących stosowania ś.o.r. Czy taka sytuacja nadal będzie miała miejsce, o tym zadecydują kontrole w następnych latach.

6. W celu zapewnienia bezpieczeństwa konsumenta istnieje ciagle potrzeba prowadzenia regularnej kontroli pozostałości ś.o.r. w uprawach płodów rolnych oraz konieczność monitorowania prawidłowości wykonywania zabiegów przez rolników, przestrzegania okresów karencji oraz stosowania się do zaleceń ochrony roślin.

\section{Literatura / References}

Chmiel Z. 1979. Spektrofotometryczne oznaczanie śladowych pozostałości dwutiokarbaminianów w materiale roślinnym. Chem. Anal. 24: 505-511.

Łozowicka B. 2010. Studium nad pozostałościami środków ochrony roślin w płodach rolnych północno wschodniej Polski. Rozpr. Nauk. Inst. Ochr. Roślin - PIB, zeszyt 21, 177 ss.

Łozowicka B., Hrynko I., Jankowska M., Rutkowska E., Kaczyński P., Janowicz T. 2011. System wczesnego ostrzegania o niebezpiecznej żywności i paszach (RASFF) w odniesieniu do pozostałości środków ochrony roślin w płodach rolnych północnowschodniej Polski. [Rapid alert system for food and feed (RASFF) for pesticide residues in crops from north-eastern Poland]. Prog. Plant Prot./Post. Ochr. Roślin 51 (2): 990-995.

Łozowicka B., Hrynko I., Rutkowska E., Jankowska M., Kaczyński P., Janowicz T. 2012. Pozostałości środków ochrony roślin w owocach i warzywach z północno-wschodniej Polski (2008-2011). [Pesticide residues in fruit and vegetables from north-eastern Poland (2008-2011)]. Prog. Plant Prot./Post. Ochr. Roślin 52 (2): 423-430.

Łozowicka B., Kaczyński P. 2009. Determination of carbendazim, linuron and glyphosate residues by HPLC method. Pol. J. Environ. Stud. 18 (2B): 100-104.

Nowacka A., Gnusowski B., Walorczyk S., Drożdżyński D., Wójcik A., Raczkowski M., Hołodyńska A., Barylska E., Ziółkowski A., Chmielewska E., Rzeszutko U., Giza I., Łozowicka B., Kaczyński P., Rutkowska E., Szpyrka E., Rupar J., Rogozińska K., Machowska A., Słowik-Borowiec M., Kuźmienko A., Szala J. 2009. Pozostałości środków ochrony roślin w płodach rolnych (rok 2008). [Pesticide residues in crops (2008)]. Prog. Plant Prot./Post. Ochr. Roślin 49 (4): 1903-1917.

Nowacka A., Gnusowski B., Walorczyk S., Drożdżyński D., Wójcik A., Raczkowski M., Hołodyńska A., Barylska E., Ziółkowski A., Chmielewska E., Rzeszutko U., Giza I., Jurys J., Łozowicka B., Kaczyński P., Rutkowska E., Jankowska M., Szpyrka E., Rupar J., Rogozińska K., Kurdziel A., Machowska A., Słowik-Borowiec M., Kuźmienko A., Szala J., Sadło S. 2010. Pozostałości środków ochrony roślin w płodach rolnych (rok 2009). [Pesticide residues in agricultural products (2009)]. Prog. Plant Prot./Post. Ochr. Roślin 50 (4): 1947-1962.

Nowacka A., Gnusowski B., Walorczyk S., Drożdżyński D., Raczkowski M., Hołodyńska A., Frąckowiak D., Wójcik A., Ziółkowski A., Rzeszutko U., Domańska I., Jurys J., Łozowicka B., Kaczyński P., Rutkowska E., Jankowska M., Hrynko I., Szpyrka E., Rupar J., Rogozińska K., Kurdziel A., Słowik-Borowiec M., Michel M., Kuźmienko A., Szala J. 2011. Pozostałości środków ochrony roślin w płodach rolnych (rok 2010). [Pesticide residues in polish crops (2010)]. Prog. Plant Prot./Post. Ochr. Roślin 51 (4): $1723-1738$.

Nowacka A., Gnusowski B., Walorczyk S., Drożdżyński D., Raczkowski M., Hołodyńska A., Frąckowiak D., Wójcik A., Ziółkowski A., Przewoźniak M., Swoboda W., Rzeszutko U., Domańska I., Jurys J., Łozowicka B., Kaczyński P., Rutkowska E., Jankowska M., Hrynko I., Szpyrka E., Rupar J., Rogozińska K., Kurdziel A., Słowik-Borowiec M., Szala J., Szponik M., Michel M. 2012. Pozostałości środków ochrony roślin w płodach rolnych (rok 2011). [Pesticide residues in Polish crops (2011)]. Prog. Plant Prot./Post. Ochr. Roślin 52 (4): 1106-1116.

Rozporządzenie WE 2005. Rozporządzenie (WE) nr 396/2005 Parlamentu Europejskiego i Rady Europy z dnia 23 lutego 2005 roku z późn. zm. w sprawie najwyższych dopuszczalnych poziomów pozostałości pestycydów w żywności i paszy pochodzenia roślinnego i zwierzęcego oraz na ich powierzchni, zmieniające dyrektywę Rady 91/414/EWG (Dz. Urz. L 70, str. 1 z 16.03.2005).

$\mathrm{SANCO} / 12495 / 2011$. Metod Validation and Quality Control Procedures for Pesticide Residues Analysis in Food and Feed, $40 \mathrm{pp}$.

Ustawa z dnia 18 grudnia 2003 r. o ochronie roślin. 2004. (Dz. U. z dnia 27 stycznia 2004 r. Nr 11, poz. 94 z późn. zm). http://isap.sejm.gov.pl/DetailsServlet?id=WDU20040110094, dostęp: 05.03.2013. 